\title{
Contradições nas políticas educacionais: garantia de aprendizagem ou manutenção da exclusão?
}

\section{Contraditions in educational politics: is it a garantee for learning or the} remaining of exclusion?

\author{
Luci Vieira Catellane* \\ Fundação Universidade Federal de Rondônia \\ Marli Lúcia Tonatto Zibetti** \\ Fundação Universidade Federal de Rondônia
}

Resumo A partir de uma perspectiva crítica de psicologia e educação, a qual considera que as raízes históricas dos problemas educacionais são forjadas no bojo de uma sociedade desigual, este ensaio discute as contradições nas políticas educacionais em Rondônia, que propõem melhorar a qualidade do ensino, por meio de programas de correção de fluxo ou do encaminhamento dos estudantes para a EJA. As discussões foram construídas a partir de diferentes estudos que permitem problematizar as situações de inclusão/exclusão, à luz das políticas públicas implantadas nesse contexto, as quais indicam ausência de investimentos no sentido de melhorar o ensino de forma a garantir a apropriação dos conhecimentos para todos, em vez da adoção de medidas pontuais que não enfrentam a manutenção de processos de exclusão no interior das escolas.

PALAVRAS-CHAVE: Políticas educacionais; Ensino fundamental; Correção de fluxo.

Abstract We propose to discuss the issue from the critical perspective on psychology and education, considering that historical roots of educational problems are forged in the midst of an unequal society. In this paper we discuss the contradictions in educational policies in Rondonia, which aim to improve the quality of learning/teaching through programs of students flow correction by forwarding them to EJA - Adults and Young Adult Education. The discussions were built from different studies that allowto analyzesituations of inclusion/exclusion in the light of the public policies implemented in this context. One can perceive the lack of investment to improve teaching/learning in order to ensure appropriation of knowledge to all, instead of adopting ad hoc measures that do not face the exclusion processes within schools.

KEYWORDS: Educational policies; Elementary School; Correction flow. 


\section{Introdução}

$\mathrm{O}$ acesso ao ensino fundamental e a obrigatoriedade de frequência à escola até os 14 anos são direitos garantidos pela Constituição Federal de 1988 e pela LDB 9394/96. A partir de 2016, em atenção à Emenda Constitucional 59/2009, a frequência exigida passará a ser de quatro a 17 anos, ampliando-se consideravelmente a duração do ensino obrigatório. No entanto, como já investigado por Patto (1991), o ingresso, permanência e conclusão das várias etapas da escolarização não são alcançados de modo linear por todos os estudantes e, dessa forma, é produzido dentro do ambiente escolar um contingente de excluídos aos quais a escola não tem conseguido oportunizar a aprendizagem do conhecimento científico sistematizado, função principal dessa instituição, segundo Saviani (2005).

Muitos meninos e meninas continuam passando pelo processo de escolarização sem aprenderem o mínimo necessário e, apesar de alguns educadores reconhecerem as deficiências da escola, as explicações ainda se voltam, na maioria das vezes, para o indivíduo: suas condições financeiras, falta de estrutura familiar, desinteresse dos aprendizes e problemas de cunho psicológico e emocional (PATTO, 2000).

Tais dificuldades têm produzido situações de exclusão dentro das redes de ensino, pois, ao mesmo tempo em que se amplia para os estudantes do ensino regular a duração da jornada, aumentando o tempo em que permanecem na escola, tem-se expurgado dessa mesma escola "aqueles" que não conseguiram obter êxito nas diferentes etapas estabelecidas pelo percurso escolar. Assim, ao invés de modificarmos as formas de ensino para garantir aprendizagens efetivas a todos, estão sendo diferenciados os percursos para atendimento aos considerados mais e menos aptos. A aprendizagem tem sido tratada nesses projetos como aptidão natural, algo inato ao ser humano que alguns possuem e outros não.

O conceito de aptidão passou a ser utilizado com essa conotação a partir do século XVIII e serviu para explicar a manutenção das desigualdades após a Revolução Francesa. Com a promessa de uma sociedade baseada na liberdade, igualdade e fraternidade a burguesia que subiu ao poder naquele momento precisava de algo que explicasse a noção de mérito individual, ou como esclarecer que nem todos (por exemplo, a classe operária) subiriam ao poder? E este mesmo "conceito" continua servindo como suporte nas sociedades capitalistas desiguais para dar sustentabilidade ao discurso de igualdade de oportunidades. Ora, se temos uma sociedade igualitária na qual todos possuem os mesmos direitos e oportunidades, só se explica o sucesso de alguns e o fracasso de muitos a partir de características individuais como ser ou estar apto.

Essa justificativa para o fracasso, como condição individual, tem se mantido há muitos anos e vem se perpetuando no interior da escola e da sociedade, como apontou Bisseret

Como a nova sociedade as instituições escolares são colocadas como igualitária, a causa das desigualdades só pode ser atribuída a um dado "natural". Essa ideologia justificadora se reforçará pouco a pouco, apoiando-se nas descobertas científicas (antropometria, pri- 
meira metade do século XIX; ciências humanas, a partir do final do século XIX), que ela sempre pretende reinterpretar de acordo com sua lógica, e cuja problemática, às vezes, conduz. (BISSERET, 1979 p. 31).

Como se vê no fragmento citado, essa noção serviu, e ainda serve, para dar explicações biológicas a questões sociais, tentando tornar diferentes e menos aptos os desfavorecidos pelo sistema econômico, como mulheres, negros, pobres em geral. A noção de aptidão mascara as desigualdades produzidas por um sistema econômico no qual não há espaço para todos. Dessa forma, criam-se situações de exclusão ou inclusão marginal, ou seja, os sujeitos estão dentro, fazem parte do sistema, estão incluídos nele, mas não usufruem dos benefícios desta inclusão.

Para Martins (2009), essa configuração se dá a partir das políticas econômicas vigentes no Brasil e em outros países que seguem o modelo neoliberal: "[...] implicam a proposital inclusão precária e instável, marginal” (MARTINS, 2009, p. 20), porque, de uma forma geral, estas políticas não são propriamente políticas de exclusão, mas políticas de inclusão marginalizante que absorvem de forma precária atendendo às necessidades de manutenção no sistema daqueles que estão à margem.

$\mathrm{Na}$ educação não poderia e não é diferente. Com a ampliação da oferta de matrículas, a rede escolar acaba absorvendo mais do que o financiamento da educação pode dar conta. Ao inchar e "estufar" um setor, com a saturação dos espaços e novas demandas por acesso, buscam-se formas para aliviar a pressão. As medidas adotadas geralmente são imediatistas que passam a aparência de benefício aos principais envolvidos, os alunos, que por algum motivo não conseguiram ter uma trajetória escolar de contínuo sucesso.

Considerando elementos apontados em diferentes estudos sobre os processos de escolarização no Estado de Rondônia, este ensaio tem por objetivo problematizar as políticas públicas voltadas ao atendimento de estudantes dos anos finais do ensino fundamental, a fim de refletir sobre propostas desiguais de atendimento a jovens de diferentes segmentos sociais.

\section{Novas medidas para velhos problemas}

"A história brasileira da educação escolar pública é feita de descaso" (PATTO, 2005, p. 181). A frase resume o que comparece nos discursos de educadores, pois há um descaso com quem utiliza e trabalha na escola pública. Escolas cheias, com professores mal formados, mal remunerados e em condições precárias de trabalho, onde são aplicadas as políticas públicas voltadas para soluções imediatas dos dados negativos do rendimento escolar, mascarando as reais causas da situação e vendendo a imagem que se está tentando resolver os problemas educacionais no país.

Nossos problemas são de longa data e a partir do momento em que a sociedade se torna mais complexa em termos de exigência de conhecimentos, estes problemas se agravam. O conhecimento sistematizado é direito de todos, e se apropriar desse e da cultura escrita em uma sociedade letrada deve ser garantia fundamental. A escola 
não é a detentora das soluções para os problemas sociais enfrentados no país, no entanto, devemos considerar que ela representa uma significativa esperança de ascensão econômica e social àqueles menos favorecidos.

Nos últimos anos, o Brasil tem conseguido inserir praticamente todas as crianças na escola. De acordo com Portela e Adrião (2007), chegamos ao ano 2000 com $97,1 \%$ de matrícula dos estudantes de sete a 14 anos no ensino fundamental. No entanto, à medida que avançam no processo de escolarização, há um afunilamento. Segundo dados do censo escolar 2012, o Brasil possui, hoje, 10,6 milhões de alunos na faixa etária entre 15 e 17 anos, o que corresponde à população potencial do ensino médio. Contudo, o número de matrículas nesta etapa de escolarização soma 8,4 milhões de estudantes. Ou seja, as crianças foram inseridas na escola, porém, ainda não conseguimos cuidar para que o processo de escolarização garanta aos estudantes a conclusão da educação básica de forma linear e satisfatória.

Cuidar do processo de escolarização significa investir no estudante enquanto participante do sistema de uma forma que abranja todas as etapas de escolarização, da educação infantil ao ensino médio, garantindo a todos a apropriação dos conhecimentos necessários à continuidade dos estudos e à inserção consciente nos processos sociais.

De acordo com Patto (1991), a educação brasileira foi pensada no bojo de ideias e concepções racistas e biologizantes sobre o comportamento humano. Em outras palavras, no fogo cruzado de preconceitos e estereótipos sociais, cientificamente validados, do ideal liberal da igualdade de oportunidades, foram geradas ideias que interfeririam nos rumos da política, da pesquisa e das práticas educacionais.

Desta forma, sempre que são propostas medidas para o enfrentamento dos péssimos resultados obtidos pelas escolas brasileiras, constatamos a atualidade dessas questões. Citando o Estado de Rondônia, que tem sido palco para os inúmeros programas oferecidos pelo governo federal, podemos apontar a multiplicidade de iniciativas voltadas à superação das dificuldades escolares por meio de medidas pontuais, compensatórias, que se voltam à população com menor rendimento, sem modificar de forma substancial práticas classificatórias e excludentes no ensino regular que historicamente têm marcado a educação brasileira. Assim, programas como o Mais Educação, o Projeto Salto de correção de fluxo e a própria Educação de Jovens e Adultos têm se configurado como iniciativas voltadas a corrigir o baixo desempenho de contingentes de estudantes que ano após ano fracassam nas escolas de ensino regular.

Gemelli (2013), ao estudar o Programa Mais Educação, voltado à ampliação da jornada em uma escola na capital do Estado de Rondônia, afirma que o programa "[...] faz parte de um rol de políticas públicas que vêm sendo implantadas nas escolas públicas brasileiras, nas últimas décadas, com o intuito de promover a qualidade da educação nacional" (GEMELLI, 2013, p. 36).

Criado pela portaria interministerial n. 17/2007 e operacionalizado pela Secretaria de Educação Continuada, o programa tem como objetivo ampliar a jornada escolar para no mínimo $7 \mathrm{~h}$ diárias. Acontece no contraturno das atividades escolares 
regulares que oferece oficinas que são agrupadas em dez macrocampos: a) acompanhamento pedagógico; b) meio ambiente; c) esporte e lazer; d) direitos humanos em educação; e) cultura e artes; f) cultura digital; g) promoção da saúde; h) educomunicação; i) investigação no campo das ciências da natureza; j) educação econômica.

De acordo com a autora, o estudo conclui que existem limitações e equívocos no programa de ampliação da jornada escolar, pois a forma como essa ampliação tem sido realizada não tem proporcionado articulação entre as atividades regulares da escola e as atividades desenvolvidas com os estudantes no contraturno. Os profissionais envolvidos, contratados como monitores, em caráter precário e sem formação adequada, são meros aplicadores de atividades.

A contradição entre o discurso que defende a ampliação da jornada para os estudantes do ensino regular com vistas a melhorar a qualidade da escola pode ser evidenciada quando analisamos a forma como esta ampliação é feita: atividades de reforço escolar para aqueles que apresentam baixo rendimento e enriquecimento cultural para os que alcançam as médias escolares, constituindo-se percursos diferenciados e empobrecidos que vão segregando e estigmatizando determinados contingentes no interior da escola que continua a produzir exclusão (GEMELLI, 2013).

Assim, as propostas de ampliação da jornada têm se caracterizado como momentos de lazer, acolhimento social e disciplinamento, distanciando os estudantes do acesso aos conteúdos curriculares. Como resultado, acentua-se a dualidade apontada por Libâneo (2012) entre uma escola "do conhecimento para os ricos" e outra escola "do acolhimento social para os pobres".

Questionamos essas ações pela impossibilidade que apresentam de problematizar e modificar a organização e o funcionamento das instituições escolares. Sem que se analisem e questionem os processos de ensino desenvolvidos, bem como as práticas seletivas e preconceituosas adotadas pelas escolas, a não aprendizagem é recorrentemente atribuída como responsabilidade dos estudantes para os quais são propostas atividades complementares, ou projetos específicos para recuperar o que nunca tiveram, enquanto a escola não sofre nenhuma alteração e continua a produzir exclusão.

Este tipo de ação para o enfrentamento das dificuldades escolares se materializa em outro projeto implantado no Estado em 2013 e que é a grande aposta do governo para "corrigir o fluxo escolar" nos anos finais do ensino fundamental $\left(6^{\circ}\right.$ ao $9^{\circ}$ ano) e educação de jovens e adultos (EJA) de ( $5^{a}$ a $8^{a}$ séries). Trata-se do Projeto Salto de Correção do Fluxo Escolar, que propõe a implantação de telessalas, onde um professor polivalente esclarecerá as dúvidas dos estudantes que assistirão às aulas gravadas em DVDs e farão o percurso escolar em menos tempo, acelerando sua trajetória escolar.

O projeto atendeu em 2013, de acordo com a Secretaria de Estado da Educação (SEDUC/RO), mais de 5 mil alunos da rede pública estadual que se encontravam em distorção idade/ano. Participaram do projeto 109 escolas em 43 municípios do Estado. Foi renovado o convênio da Secretaria de Estado da Educação (SEDUC/ RO) com a Fundação Roberto Marinho para 2014 e a secretaria previa o atendimento 
de 11.751 estudantes do ensino fundamental nas modalidades regular e EJA, divididos em 390 turmas em 52 municípios do Estado. Para se matricular no projeto, o estudante deve estar com dois anos de defasagem idade/ano, ou seja, a partir de 13 anos de idade considerando a idade base de 11 anos para o ingresso no sexto ano do ensino fundamental (RONDÔNIA, 2013).

Quando nos voltamos para os dados de reprovação e abandono escolar no Estado de Rondônia, que produzem o público potencial do projeto de correção de fluxo, torna-se evidente a demanda para esse tipo de medida. No período compreendido entre 2007 e 2010, os índices de reprovação nos anos finais do ensino fundamental regular oscilaram entre 17,3 e 19,1\%, enquanto as taxas de abandono se mantiveram entre 5,2 e 7,4\% no mesmo período, de acordo com dados divulgados pelo IBGE (2010).

A taxa de reprovação tem se mantido bastante elevada enquanto que o abandono vem sofrendo redução gradativa nos últimos anos, conforme indicam dados do censo escolar 2012 que apontam para 4,5\% de evasão nesta etapa da escolarização. Entendemos que estes números podem ser creditados às políticas de bolsa escola e bolsa família que têm conseguido manter as crianças matriculadas, sem que, no entanto, se tenha garantido a aprendizagem (BRASIL, 2012).

O Projeto Salto de Correção do Fluxo Escolar tem como objetivo corrigir o fluxo, tentando criar mecanismos de aprovação que ampliem o número de concluintes no ensino fundamental, elevando o nível de escolarização básica da população. A fórmula encontrada para resolver a situação, entretanto, leva a problematização se esta medida está voltada para a efetiva aprendizagem dos estudantes ou apenas para diminuição do número de sujeitos em situação de distorção idade/ano.

Segundo informações da Seduc, pretende-se "acelerar a aprendizagem" utilizando a metodologia Telecurso Ensino Fundamental da Fundação Roberto Marinho com a adoção de telessalas nas escolas e a unidocência (RONDÔNIA, 2013). Considerando a grade curricular de sexto ao nono ano ou a grade de quinta a oitava série da EJA, podemos nos perguntar: quem exercerá essa unidocência? Qual seria a formação acadêmica deste professor polivalente?

Ao reduzir o número de professores no processo de ensino e acelerar o tempo de conclusão do ensino fundamental, pretende-se oferecer ainda menos a quem já se encontra em defasagem de aprendizagem. De acordo com Vieira e Machado (2005, p. 226, grifo das autoras): "A produção escolar de alunos fracassados não se altera com os projetos que visam 'regularizar o fluxo' do alunado pelos oito anos do ensino fundamental- ou seja, fazê-los escoar mais rápido".

O projeto prevê formação docente, no entanto, trata-se de formação que garante o trato com o material, visto que está sendo ministrada pela própria fundação. Tais políticas têm caráter de coisificação do ser humano. De acordo com Chauí (1980, p. 33), o recurso audiovisual como normalmente é utilizado na educação brasileira "[...] tende a transformar a igualdade educacional em nivelamento cultural pelo baixo nível dos conhecimentos transmitidos". 
Esta situação nos remete às considerações de Martins:

\begin{abstract}
O homem deixa de ser o destinatário direto do desenvolvimento, arrancado do centro da história para dar lugar à coisa, ao capital, o novo destinatário fundamental da vida. Isso torna os problemas daí decorrentes complicados e confusos em face de outros modos de ver o mundo. Sobretudo porque os agentes, voluntários ou involuntários, dessas políticas, podem oferecer e estão oferecendo suas próprias alternativas às vítimas do atual processo de desenvolvimento, que são as alternativas da coisificação e da adaptação excludente, da alegria pré-fabricada e manipulada. (MARTINS, 2009, p. 20).
\end{abstract}

Podemos considerar que o modelo proposto neste projeto busca fazer com que aqueles que não se adequaram à escola a deixem de forma "politicamente satisfatória". Ou seja, como escolarizados, com uma certificação, mas sem aprender os conteúdos do ensino básico, o que se coaduna com a lógica capitalista que, de acordo com Martins (2009), transforma tudo, inclusive o saber e o ser humano em mercadoria. $\mathrm{O}$ autor afirma que: "A lógica do sistema capitalista é o mercado, é o movimento, é a circulação: tudo tem de ser sinônimo ou equivalente de riqueza que circula, de mercadoria" (MARTINS, 2009, p.30). Para atender esta lógica, a escola precisa ter um fluxo corrente, porque uns precisam sair para outros entrarem, porém, novamente a saída não é buscada por meio da melhoria do ensino nas classes regulares, de maneira a elevar o índice de aproveitamento para todos os estudantes. Mas por meio de um programa específico para atender os já excluídos.

Considerando que o ensino regular tem sido acompanhado de forma sistemática pelos sistemas de avaliação externa, cujos resultados têm sido divulgados sob a forma de rankings como o Índice de Desenvolvimento da Educação Básica (IDEB) e o Exame Nacional de Ensino Médio (ENEM), outra medida tem sido adotada para elevar os resultados obtidos pelo ensino regular, sem que se invista maciçamente na melhoria da escola: o encaminhamento dos adolescentes em defasagem idade/série para a EJA. Estudiosos desta temática (CARVALHO, 2010; ROMANIO, 2011; SILVA, 2012; PRATA, 2013) têm apontado um número expressivo de adolescentes na educação de jovens e adultos. Estes jovens poderiam estar no ensino regular, no entanto, a partir de 15 anos, independentemente de estarem ou não trabalhando, os jovens estão migrando para a EJA, criando-se, desta forma, a ideia de que poderão passar mais rápido pela escola já que a modalidade é condensada e duas séries são cursadas em um ano.

Entretanto, a ineficiência desse modelo se materializa na evasão escolar desses jovens na modalidade de EJA que historicamente tem se mantido extremamente alta conforme pesquisas de Silva (2012), Prata (2013) e Lima (2015). Ou seja, cria-se a falsa ideia de aceleração dos estudos, uma vez que estes jovens se matriculam, saem da escola e a ela retornam novamente, o que, segundo Patto, pode ser considerado como mais um mecanismo sutil de expulsão.

Em geral, as crianças são mantidas na escola durante muitos anos, até que mecanismos escolares mais ou menos sutis de expulsão acabem por se impor. Tirar da escola uma criança que 'vai bem' não é a regra, o que contraria a versão do senso comum, segundo a qual 
a desvalorização da escola pelos pobres seria a principal causa da evasão escolar. (PATTO, 1992, p. 118).

As afirmações de Patto, embora referindo-se às crianças, aplicam-se aos adolescentes dos anos finais do ensino fundamental que apresentam um percurso de reprovações e aos poucos vão sendo expulsos da escola, como indesejáveis, sendo encaminhados para a EJA, para evitar que influenciem negativamente as avaliações externas. Assim, teríamos a configuração do grupo que Bourdieu (1997, p. 480) nomeia como os "excluídos na escola" ou o "problema da inclusão marginal" conforme destacado por Martins (2009, p. 26), uma vez que para o autor, na lógica capitalista, ninguém está propriamente excluído, mas incluído de forma marginalizada.

De acordo com Bourdieu, (1997, p. 485), a escola exclui de forma continuada em todos os níveis "[...] e mantém no próprio âmago aqueles que ela exclui, simplesmente marginalizando-os nas ramificações mais ou menos desvalorizadas". No caso, na educação de jovens e adultos, historicamente desvalorizada e que tem acumulado mais esta dificuldade de lidar com um público extremamente diversificado em termos etários, com uma carga horária reduzida.

Com a abertura de vagas e novos projetos na educação de jovens e adultos para o atendimento aos adolescentes cria-se a ideia de que está sendo oferecida a esses estudantes uma aceleração dos estudos de maneira que possam recuperar os anos perdidos e ao mesmo tempo oferecer escolarização a quem não teve oportunidade na idade certa. Entretanto, conforme considerações de Chauí (1980, p. 25), estaríamos diante de um discurso ideológico que tem sido extremamente eficiente:

Como forma do exercício da dominação de classe, a eficiência da ideologia depende de sua capacidade para produzir um imaginário coletivo em cujo interior os indivíduos possam localizar-se, identificar-se e, pelo auto reconhecimento assim obtido, legitimar involuntariamente a divisão social. (CHAUÍ, 1980, p. 25).

As contradições que caracterizam os investimentos em políticas públicas no Estado de Rondônia podem ser desveladas de maneira a revelar a ideologia que sustenta o discurso de melhoria da qualidade do ensino, pois ao mesmo tempo em que temos projetos para "acelerar" o percurso educacional dos estudantes, fazendo-os passar de forma mais rápida pela escola, não vemos alterações substanciais na forma de funcionamento do ensino regular de maneira que a produção da exclusão continuará sendo a tônica da escola. Quando anteriormente falamos de cuidar do processo estamos indicando cuidar da escolarização básica dos estudantes, ler, escrever, calcular, conhecer arte, literatura, história, ciência e filosofia, de forma a instrumentalizar estes estudantes para que no futuro possam participar da sociedade de forma ampla. Não apenas como um capital humano no mercado de trabalho, mas como um ser que possa produzir sua vida de forma responsável e, principalmente, de maneira consciente.

Implantando projetos compensatórios, dirigidos a segmentos distintos do processo educacional, na mesma unidade da federação e às vezes na mesma instituição, os recursos para a educação são pulverizados aqui e ali e impedem mais investimentos no processo escolar básico desses estudantes. 


\section{Considerações finais}

As contradições nas políticas públicas de enfrentamento ao fracasso escolar instituídas nas escolas brasileiras podem ser percebidas em diferentes situações: ampliação da jornada escolar como argumento para melhorar a qualidade do ensino, sem a contratação de profissionais habilitados para oferta de ensino qualificado e nenhuma medida efetiva de alteração nas práticas de sala de aula que têm produzido contingentes de estudantes que não aprendem. Valorização do conhecimento nas avaliações nacionais que compõem o ranking que destaca as escolas com melhores resultados e desvalorização deste mesmo conhecimento nas atividades de ampliação da jornada nas escolas que atendem crianças e jovens das escolas públicas periféricas que recebem os programas como Mais Educação. Esforço nacional pela matrícula de todas as crianças no sistema escolar e pouquíssimos investimentos na criação de condições infraestruturais para produção de uma escola que garanta o acesso ao conhecimento.

Essas contradições evidenciam o modelo neoliberal que sustenta a política nacional, cujo discurso se pauta pela democratização das oportunidades, explicando o sucesso e o fracasso pela ideologia das aptidões naturais, ou pelo esforço individual que fundamenta o princípio da meritocracia.

Trabalhar no sentido de desvelar estas contradições significa evidenciá-las e defender a necessidade de oferecer condições de aprendizagem aos estudantes conforme suas necessidades que são desiguais em decorrência das condições de vida em que estão inseridos. Ou seja, as escolas a que têm acesso os estudantes de baixa renda precisam melhorar a qualidade do ensino oferecido em todos os sentidos: com melhores professores, melhores condições de estudo, ampliação do tempo de efetivo trabalho com os conteúdos, modificação das práticas de ensino e não apenas a repetição das mesmas atividades oferecidas em sala de aula que não alcançaram bons resultados, em horário de reforço (acompanhamento pedagógico), com monitores sem formação que oferecem aulas de qualidade duvidosa para preencher o tempo desses estudantes na escola.

Além disso, não se pode entender que a solução para o rendimento escolar se encontra em programas de aceleração dos estudos a quem está em defasagem idade/ ano, sem considerar as dificuldades desses alunos.

A psicologia por um bom tempo esteve a serviço da classe que detinha o poder tentando explicar, a partir de instrumentos "cientificamente validados", diferenças sociais como diferenças individuais, culpabilizando o marginalizado pela situação a qual ele é dolorosamente submetido.

Depois de tantos anos e muitas discussões na área, ainda estamos discutindo o problema do fracasso escolar sem considerar, em muitas produções, as condições de funcionamento da escola. Analisar as políticas públicas que se encontram em curso nas escolas brasileiras nos leva a considerar que essa instituição tem se configurado mais como uma instituição assistencialista na qual são mantidas crianças em troca de ajuda financeira, em um ambiente que não tem conseguido garantir-lhes o que se espera da escola: um espaço de aprendizagem e de transmissão do conhecimento sistematizado e acumulado pela humanidade. 
Chega a ser doloroso aceitar que a escola pública para o pobre tem se configurado como espaço de assistência social ou no máximo de certificação e acolhimento em que se considera, como afirmam Vieira e Machado (2005, p. 227), que "o bom da escola é que ela tira as crianças da rua”.

\section{Referências}

BISSERET, A. A ideologia das aptidões naturais. In: DURAND. J. C. G. (Org.). Educação e hegemonia de classe. Rio de Janeiro: Zahar, 1979. p. 30 - 67.

BOURDIEU, P. Os excluídos do interior. In: A miséria do mundo. Petrópolis: Vozes, 1997. p. 481-490.

BRASIL. Ministério da Educação. Instituto Nacional de Estudos e Pesquisas Educacionais Anísio Teixeira. Censo da educação básica: 2012 - resumo técnico. Brasília, DF, 2012.

CARVALHO, R. V. A Juventude na educação de jovens e adultos: estudo das práticas pedagógicas no ensino fundamental, fase II, e ensino médio. 2010. 223f. Dissertação (Mestrado em Educação)- Universidade Tuiuti do Paraná: Curitiba, 2010.

CATELLANE, L. V. O adolescer da EJA: a escolarização de adolescentes na educação de jovens e adultos. 2015. Dissertação (Mestrado)- Programa de Pós-Graduação em Psicologia. Fundação Universidade Federal de Rondônia: Porto Velho, 2015.

CHAUÍ, M. S. Ideologia e educação. Educação e Sociedade, São Paulo, v. 5, p. 24-40, 1980.

GEMELLI, D. S. Programa mais educação: um olhar da psicologia sobre a ampliação da jornada escolar. Dissertação (Mestrado) - Fundação Universidade Federal de Rondônia, Porto Velho, 2013.

IBGE. Aprovação, reprovação e abandono: ensino fundamental. Séries históricas e estatísticas. Brasília, DF, 2010. Disponível em:<http://seriesestatisticas.ibge.gov.br/series.aspx?no $=9 \& \mathrm{op}=2 \& \mathrm{vcodigo}=\mathrm{M} 101 \& \mathrm{t}=$ aprovacao-reprovacao-abandono-ensino-fundamental-serie $>$. Acesso em: 28 dez. 2013.

LIMA, L. V. C. O adolescer da EJA: a escolarização de adolescentes na educação de jovens e adultos. 2015. Dissertação (Mestrado)- Programa de Pós-Graduação em Psicologia. Fundação Universidade Federal de Rondônia: Porto Velho, 2015.

LIBÂNEO, J. C. O dualismo perverso da escola pública: escola do conhecimento para os ricos, escola do acolhimento social para os pobres. Educação e Pesquisa, São Paulo, v. 38, n. 1, p. 1328, jan./mar. 2012.

MARTINS, J. S. Exclusão social e a nova desigualdade. São Paulo: Paulus, 2009.

PATTO, M. H. S. A produção do fracasso escolar: histórias de submissão e rebeldia. São Paulo: T.A Queiroz, 1991.

. Família pobre e escola pública: anotações sobre um desencontro. Psicologia USP, São Paulo, v. 3, p. 107-121, 1992.

. Mutações do cativeiro: escritos de psicologia e política. São Paulo: Edusp, 2000.

. Sob o signo do descaso. In: PATTO, M. H. S. (Org.). A cidadania negada: políticas públicas e formas de viver. São Paulo: Casa do Psicólogo, 2005. p 181-188.

PORTELA, R. O.; ADRIÃO, T. O ensino fundamental. In: PORTELA, R. O.; ADRIÃO, T. (Org.). Organização do ensino no Brasil: níveis e modalidades. 2. ed. São Paulo: Xamã, 2007. p. 31-46. 
PRATA, J. M. "Somos tão jovens": estudo geracional sobre juventude na EJA no município de Mesquita. 2013. 115f. Dissertação (Mestrado em Educação)-. Faculdade de Educação da Baixada Fluminense-Universidade do Estado do Rio de Janeiro: Duque de Caxias, 2013.

ROMANIO, M. B. A Implementação da Política de Educação de Jovens e Adultos (EJA) em uma Escola Municipal De Vitória/ES: apostas e tensionamentos. 2011. 93f. Dissertação (Mestrado em Psicologia Institucional)- Universidade Federal do Espírito Santo, Vitória, 2011.

RONDÔNIA. Secretaria de Estado de Educação. Projeto Salto de Correção de Fluxo é renovado para 2014. Porto Velho, 2013. Disponível em: <http://www.seduc.ro.gov.br/portal/ index.php/noticias-all/1120-projeto-salto-de-correcao-de-fluxo-e-renovado-para-2014.html>. Acesso em: 28 dez. 2013.

SAVIANI, D. Pedagogia histórico-crítica: primeiras aproximações. 9. ed. Campinas: Autores Associados, 2005.

SILVA, F. C. de S. Realidades da educação de jovens e adultos no ensino fundamental: presencial no Município de Itaituba (PA): desafios da gestão, do planejamento e das políticas educacionais na efetivação do direito à educação em escolas da cidade e do campo. 2012.342f. Tese (Doutorado em Educação) - Universidade Estadual de Campinas, Campinas, 2012.

VIEIRA, N. P.; MACHADO, A. M. Os males do estigma. In: PATTO, M. H. (Org.). A cidadania negada: políticas públicas e formas de viver. São Paulo: Casa do Psicólogo, 2005. p.225237.

* Mestre em Psicologia pela Fundação Universidade Federal de Rondônia, Porto Velho, Rondônia, Brasil.

** Professora doutora da Fundação Universidade Federal de Rondônia, Porto Velho, Rondônia, Brasil.

Luci Vieira Catellane Lima - Athenas Grupo Educacional, Av. Transcontinental , n. 1119 Bairro Centro Ji-Paraná, Rondônia.

E-mail: lucatellane@gmail.com - marlizibetti@yahoo.com.br

Recbido em 28 de outubro de 2014

Aprovado em 26 de fevereiro de 2015 
